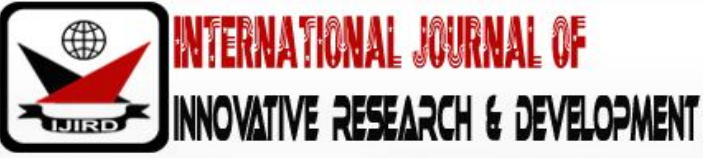

ISSN 2278 - 0211 (Online)

\section{Teaching Practice Monitoring and Supervision Experiences towards Improving Pre-Service Teacher Training in Tanzania: A Case Study of Mwenge Catholic University}

\author{
Joseph Lasway Angelista \\ Full Time Assistant Lecturer, Department of Education Curriculum and Instructions, \\ Mwenge Catholic University, Tanzania
}

\begin{abstract}
Teaching and learning in secondary schools worldwide has been influenced by many factors, among them being the qualification of teachers and their professional knowledge and skills. Teacher education has continued to become an area of concern when looking for teacher competence and efficiency in schools at all levels as it is seen to have influence the teacher practices and performance. This study therefore is aimed at finding out on how monitoring and supervision of teaching practice can improve pre-service teacher training in Tanzania. The main focus was on one university that offers a special Block Teaching Practice (BTP) that involves strong monitoring mechanism and supervision to enhance teacher trainees' professional competence. The population of this study included 200 monitors and 85 academic staff was used where by 23 monitors and 45 university academic staff was selected as a sample through simple random sampling technique. The data was collected though focus group discussion and questionnaire. The data collected was analyzed through descriptive statistics into percentage and frequencies and the qualitative patterns were organized into themes and tallied to form texts and narratives, quotes and descriptions. The findings show that monitoring and supervision during the practical training form the basis for effective pre-service teacher Education. Both monitors and supervisors are equally important in molding teacher trainees' competence and professional knowledge in preparing qualified future teachers. The study recommends that other colleges and universities offering Pre-service teacher training to adapt the monitoring mechanism to improve teacher trainees' ability to experience multiple benefits through various mentors. The study concludes that effective monitoring and supervision of teaching practice can be reliable mechanisms for improving pre-service teacher training.
\end{abstract}

Keywords: Block teaching practice, monitoring, supervision, teacher trainee

\section{Introduction}

The rationale for teaching practice is to provide opportunities for teacher trainees to put into practice different theories and skills learnt in the training courses while they are in actual school's environment. The knowledge and skills are situated in the day to day lived experiences of teachers and best understood through critical reflection of reality with others who share the same experience. By actively engaging the teacher trainees in the school situations, they will increase their professional knowledge and enhance their learning. The teacher trainees will also discover their own intellectual resources and to make them better able to work in changing job contexts. The teacher trainees (TTs) develops their own teaching skills, learn to plan, teach and evaluate the teaching in terms of the curriculum, the school community and the age and learning capacity of the students. The teacher trainees will learn how to cooperate with other teachers and parents and solve day to day challenges regarding the actual teaching service.

Tanzania Education and Training Policy (2014) state clearly that all the professional training programmes must design appropriate practical lessons where learners should be exposed to actual skills learned theoretically during the programme implementation. In teacher training programmes in particular there should be well organized and supervised teaching practice where the trainees will experience real school life teaching. This practical training expected to help teacher trainees to develop professional skills and apply the knowledge learnt to take different teachers' roles in a school context. 
For a person to be prepared to attain a professional teaching qualification it involves an intensive learning process with a number of experiences in and out of classroom. The teacher Trainees are required to develop the confidence to work with the experienced teachers and learners in real situations. The trainees need to be directed to follow practically the school practice and ministry guidelines. This experience in teaching is the integration of different kinds of knowledge. Teacher professional training also needs role models, observing experts, tact knowledge, a social network and even success stories of successful practice. Expert knowledge, it has been added on is rational knowledge with principles, rules and models and teacher trainees need to know how to apply scientific theories and techniques to complex problems. Teacher training therefore, is related to other social and political theories including aspects such as democracy, social justice equality, legitimacy, gender issues, diversity in schools, sustainable development and inclusive education to mention a few (Kagoda\& John Sentongo 2015). In this context, a teacher training programme expected to prepare a wholistic person who is able to address different issues in the society for personal and national development.

The efforts by the university are aimed at ensuring that, not only its trainees receive the best from the programme but also, they develop the required skills which they will apply when they are implementing the secondary national curriculum after their training. To strengthening this objective a number of initiatives have been put in place, including the involvement of other stakeholders such as the secondary school teachers, heads of schools, quality assurance and standards offices, District and Regional Education Officers among others.

Since 2010, Mwenge Catholic University in partnership with Christian Social Services Commission (CSSC) has been running a monitoring programme that aims at providing support to student teachers during teaching practice. The university has been orienting these monitors on learner centered techniques, lesson preparation, lesson evaluation and general teacher behavior that is expected of the teacher trainees during the teaching practice. These teachers are then sent to the schools where trainees go for teaching practice with the aim of providing guidance before the university assessor go for the general assessment.

Mushi and Lasway (2017) in a study on the higher learning students' expectations implications and achievement emphasize the significance of designing college and university programmes that prepare the learners to develop both the teaching knowledge and skills. The study emphasizes the need for knowledge and skills acquisition as one way of helping the trainees to improve the efficiency of the manpower created from a particular field. From this basis, the teacher training course that focuses on developing competent professionals through practical training has to develop measures of ensuring that this goal is achieved such as the teaching quality control through monitoring of its trainees and observe their practical performance.

Vumilia and Semali (2015) in a study about if the Mentoring and Socialization of Pre-service Teachers Improve Teacher Education, point out that teacher trainees require good basis from those already in the teaching service as their mentors or role models in order to learn the new experiences and different ways of solving challenges associated with the teaching in a school. The value of experienced teachers in serving as role models to the teacher trainees is very important during teaching practice session, since the trainees are subject to an observation and require help which is very potential for the growth of the trainees' skills and knowledge. Therefore, involving the experience teachers in monitoring and supporting of teacher trainees is of significance but the experienced teachers also need to be refreshed in order to provide a meaningful support. These initiatives are expected to be offered through in-service programmes initiated either by the Ministry or by colleges and universities that offer the teacher training programmes such as what Mwenge Catholic University is doing for enhancing its course effectiveness.

The author of this article developed interest to find out the role of monitoring and supervision of the teaching practice in enhancing pre-service teacher training programme in Tanzania and specifically in the selected university. This was because the university understudy demonstrates some special efforts in improving the efficiency of teacher trainees' practical training through the involvement of experienced teachers in the schools to support trainees when conducting teaching practice each year.

\section{Statement of the Problem}

The quality teaching during the teaching practice is ensured by thoroughly grounding the teacher trainees in their subject content areas and professional courses which include teaching methodology at the training institution and through the support trainees receive from their professors, mentors and school administrators during teaching practice. Kagoda \& John Sentongo (2015) on their study on Practicing Teachers' perceptions of Teacher Trainees:

Implications for Teacher Education hold that, the practicing teachers have a responsibility to help teacher trainees to settle in the school in different ways including encouraging and promoting best practices in the profession such as discussing topics with them to help teacher trainees understand the subject matter and show them how to write notes for students. Vumilia and Semali (2015) on the role of mentoring to the teacher trainees emphasize that the experienced teacher should offer support to the trainees' including instructional materials, guiding them on how to write the schemes of work and the lesson plans. The role of experience teachers and professional experts are expected to guide the teacher trainees on how to organize the school assembly and encourage them to address assembly; guiding them on how to handle the large classes, advising them to dress appropriately; act as models for them and allow them to administer punishments to students. Therefore, this study intends to find out how the use of monitoring (experienced secondary school teachers) and supervision during teaching practice improving the quality of the pre-service teacher training programme. 


\section{Methodology}

One month after the monitoring and supervision process, 23 monitors from different clusters and 45 university lecturers were selected using stratified sampling technique. These monitors and lecturers attended a feedback session held at the university campus to share their experiences on the monitoring and supervision process. At the end of the discussion, monitors responded in the questionnaires that were given to them as an exit tickets which required them to indicate the learned experiences, challenges and opportunities that observed during the monitoring and supervision activity. The data was analyzed into percentage and frequency and presented in tables and narratives.

\section{Findings and Discussions}

\subsection{Monitors' Rating on Student Teachers' Competence}

Monitors were asked to indicate how they perceived the competence of teacher trainees as observed during the teaching practice period. A total of 23 monitors responded to this question in a questionnaire that was given as an exit ticket and their responses are presented in table 1

\begin{tabular}{|c|c|c|c|c|c|c|c|}
\hline S/ N & Aspect & \multicolumn{2}{|c|}{ Good } & \multicolumn{2}{c|}{ Very good } & \multicolumn{2}{c|}{ Excellent } \\
\hline & & $\mathrm{F}$ & $\%$ & $\mathrm{~F}$ & $\%$ & $\mathrm{~F}$ & $\%$ \\
\hline 1 & lesson preparation and planning & 2 & 8.7 & 18 & 78.3 & 3 & 13.0 \\
\hline 2 & communication skills & 7 & 30.4 & 14 & 60.9 & 2 & 8.7 \\
\hline 3 & student engagement in learning & 4 & 17.4 & 14 & 60.9 & 5 & 21.7 \\
\hline 4 & lesson evaluation & 8 & 34.8 & 11. & 47.8 & 4 & 17.4 \\
\hline 5 & personal factors & 1 & 4.3 & 12 & 52.2 & 10 & 43.5 \\
\hline
\end{tabular}

Table 1: Monitors' Rating on Teacher Trainees' Competence

Results in table 1 show that most of the monitors who participated in the study (78.3\%) rated the teacher trainees' competence in lesson planning and preparation as being very good. The remaining $8.7 \%$ and $13.0 \%$ of them rated this aspect as being good and excellent respectively. These findings imply that, monitors consider Teacher trainees from Mwenge Catholic University to be competent in lesson preparation and planning. The competence of teacher trainees in this aspect is of paramount importance in the teaching profession as a teacher needs to plan his or her lesson for effective teaching. The competence of teacher trainees from Mwenge Catholic University regarding to planning and prepare good lessons could have resulted from the monitoring process which has been initiated and conducted since 2010 to date.

Another aspect identified by monitors was the ability of teacher trainees to engage students in lesson activities. A good number of monitors who participated in the study $(60.9 \%)$ rated the ability of teacher trainees to engage students in the lesson activities to be very good followed by $21.7 \%$ who rated it to be excellent. This implies that most of the monitors consider teacher trainees to be competent in involving students in the lesson activities. This is a good indication as it shows that teachers are well adapting to the learner centered approaches which require maximum engagement of students in the lesson. Other aspects of teacher competence identified by monitors included lesson evaluation, communication skills and personal factors. All these factors were rated by monitors as being good, very good or excellent. No aspect was rated to be poor, bad or fair. This implies that the teacher trainees from MWECAU are well equipped with the skills needed in the teaching process and they are perceived to be excelling during teaching practice.

\subsection{Monitors' Reception by Teacher Trainees}

All the monitors who responded to this question indicated most to like the reception by the teacher trainees during the monitoring activity. This implies that all the monitors were well received by the student teachers in the schools and the student teachers do value the work and feedback given by the monitors. Reasons given for such good reception included the readiness of the students to learn new concepts and ask for clarification in case of difficulties, established the good communication between the monitors, student teachers and the university assessors which ensured that the assessor had to wait for a monitor to provide assistance to the students before being assessed and given awards. Therefore, the work of monitors was considered by the teacher trainees as a pedagogical assistance to them which made it possible to acquire new knowledge and skills necessary improving their teaching profession.

Moreover, monitors indicated that, the teacher trainees showed punctuality, obedience as well as the best discipline during the monitoring session and they were ready to work on the feedback given by the monitors. This implies that teacher trainees appreciated the assistance given by the monitors as they showed the cooperation and being ready to change. Additionally, monitors indicated that the student teachers were ready to cooperate with the monitors inside and outside the class during the monitoring activities. This motivated the monitors to provide the required assistance as they realized that their assistance was valued by the teacher trainees. These finding concurs with Vumilia \& Semali (2015) who established that the school mentors play a great role in supporting teacher trainees during teaching practice as it enhances confidence and competence in teaching. 


\subsection{Monitors Reception by School Administration}

All monitors who participated in this study indicated that, they like the way teacher trainee were received by the school administration during the monitoring process. Since some of the teachers had to leave their working stations to go to other schools within their clusters for monitoring, they were given the introductory letters to be presented to the head of schools and seek for permission to conduct the monitoring process. To all the schools these monitors went, the school administration received them well and showed them all the required cooperation.

The monitors indicated that the management (heads of schools) recognized the presence of monitors and did all what was possible to ensure that the monitoring activity was well conducted. This enabled the monitors to conduct their activities freely and confidently. The good reception to the monitors by heads of the schools could have been resulted from the inception workshop conducted by MWECAU in partnership with the Christian Social Services Commission that involved the heads of schools, district educational officers and the regional educational officers in the respective clusters about the importance of the monitoring process.

Moreover, the monitors pointed out that, the heads of schools were thankful to what the teacher trainees were doing in and outside the classes and they promised to provide the required help in making the conducive teaching and monitoring process possible. This implies that the school administration had positive attitudes towards the monitoring process, being cooperative and supportive to both the monitors and the student teachers.

\subsection{Monitors Readiness to Participate in Monitoring Programme}

Monitors were asked to indicate if they were willing to participate in monitoring activities next time. All of them 23 (100\%) replied that they were ready to participate. This implies that monitors are willing to participate in the programme and when they are required to assist the university in the future they will all be ready for the activity. Monitors indicated that they will continue helping the university to meet its goals and help the teacher trainees to reach their expectations. Moreover, monitors showed the concern to help the new teachers to acquire the knowledge and skills needed in the teaching profession.

In addition to that, monitors indicated that they had acquired a lot of information about the teaching profession including lesson preparation, classroom management, participatory teaching and stress management and therefore they wanted to share these skills with teacher trainees during the field activity. Therefore, the monitoring process is seen by monitors as a vehicle for updating their knowledge and skills in the teaching profession and helping other teachers to improve their teaching for the view of improving the quality of teaching in secondary schools and hence improve the quality of education offered in these schools in the country.

\subsection{Benefits the Monitors Get from the Monitoring Programme}

Monitors were asked to state the benefits they had from the programme. All of them (100\%) agreed that the programme has been of benefit to them and identified that it helped them to develop their knowledge about teaching methods, assessment techniques and how to give constructive feedback. Other benefits they obtained included acquiring knowledge and skills used to make the lessons and schools up to date in teaching, interaction and exposure to learner centered techniques and experiences about the teaching profession and skills in managing the students' discipline.

The monitoring process therefore, has been of significant to the monitors as it does not only prepare them to help teacher trainees but also make them updated with different skills, knowledge and experiences required in the teaching profession. This was made more evidently by one monitor during the session who indicated that "I have gained knowledge about the learner centered teaching and now I am familiar with how to apply different techniques and to prepare low cost resources". Responses from the monitors show that monitoring programme is achieving its objectives and therefore should be strengthened.

\subsection{Challenges Monitors Faced During the Monitoring Activity}

Monitors were also asked to indicate the challenges they faced during the monitoring process. The major challenge identified was time constraint whereby monitors indicated to have a limited time to conduct the monitoring activity well. As monitors were required to visit each teacher trainee twice, sometimes getting that, the time was a challenge and they sacrificed their own activities for the monitoring job. The school timetables and general routines were also identified as challenges to the monitoring process as it was not easy to locate adequate time for monitoring.

Another challenge identified was geographical hardship and poor accessibility of some schools. Let it be noted that some monitors were to travel from their working stations to other schools, therefore, sometimes it was difficult to reach those schools and hence the monitoring process was negatively affected. Financial problems were also identified as a limiting factor whereby monitors indicated that the amount of money given was fixed to a particular mode of transport (public transport) and therefore, it was not possible for them to adjust or use other means of transport in reaching the schools conveniently. This sometimes caused them to arrive late at the schools and hence the monitoring activities were somehow affected. Some few teacher trainees were identified not to be so serious with the monitoring exercise and were not following the directions given by the monitors. This was made evident when the monitors indicated to have found some students with similar mistakes during the first and second visits. 


\subsection{Suggestions on How to Improve the Monitoring Programme}

During training more, monitors were identified as being the most effective way of improving the monitoring programme. The presence of more monitors in the programme could reduce the number of the students each monitor has to visit and ensure that all the teacher trainees visited by a monitor before assessment. This will make MWECAU teacher trainees more competent in teaching methods, assessment techniques, classroom management and lesson evaluations. In addition, monitors indicated that more time should be given for the monitoring process as the current two weeks set for the activity are not enough. Visiting the students in two occasions needs time as there should be enough time for a student to accommodate the feedback given during the first visit. Moreover, financial support given to the monitors should be improved to make it possible for monitors to travel to the different schools in the nearby successfully.

\subsection{The Block Teaching Practice Feedback Session with the University Lecturers}

The BTP coordinating team and the task force conducted a feedback session with the university lecturers on the following areas which were covered during the focus group discussion on Personal experiences encountered during the teaching practice supervision, the lessons learnt during the BTP, Strong areas and Areas for improvement. The main objectives of conducting the feedback session was to get first hand information on the BTP experiences from the lecturer's perspectives and also to identify where the exercise was strong and suggestions on how the practice can be improved. About $47 \%$ of the university lecturers attended the discussion and all their inputs were noted down and presented in the following section. Some of the experiences reflect the burning issue in teacher training but also in the general teaching performance in secondary schools.

\section{Supervisors (Assessors) Experiences}

When the university lecturers were asked to share their experiences through small group discussion they encountered during the Teaching Practice they came up with the following.

\begin{tabular}{|c|c|c|c|}
\hline S/ No & Experience & F & $\mathbf{\%}$ \\
\hline 1 & $\begin{array}{c}\text { More student teachers managed to teach through practical activities and the y } \\
\text { involved their students in carrying out experiments }\end{array}$ & 35 & 77.7 \\
\hline 2 & $\begin{array}{c}\text { Most of the students were ever ready waiting for assessments and grading as } \\
\text { compared to the previous years }\end{array}$ & 40 & 88.8 \\
\hline 3 & $\begin{array}{c}\text { The school leadership and administration were very positive towards the teacher } \\
\text { trainees and provided appropriate support to them }\end{array}$ & 45 & 100 \\
\hline 4 & $\begin{array}{c}\text { The geographical location (mapping) of supervisors were improved and enough } \\
\text { information about the schools were indicated in the list which was given to the } \\
\text { lecturers and monitors }\end{array}$ & 43 & 95.5 \\
\hline 5 & Our student teachers were liked by the teachers and students in the schools & 45 & 100 \\
\hline 6 & $\begin{array}{c}\text { The commitment of the teacher trainees trusted to different school responsibilities } \\
\text { even without close supervision of the experienced teachers }\end{array}$ & 45 & 100 \\
\hline 7 & $\begin{array}{c}\text { Some school programmes were interfered with the seasonal changes including } \\
\text { planting and weeding of school farms which confused both the supervisors and } \\
\text { teacher trainees. }\end{array}$ & 20 & 44 \\
\hline 8 & $\begin{array}{c}\text { Travelling difficulties between the schools especially where motor cycles were the } \\
\text { major means of transport }\end{array}$ & 10 & 22 \\
\hline 9 & $\begin{array}{c}\text { Culture and especially religion has a great influence on how teaching and learning } \\
\text { takes place in the schools. }\end{array}$ & 20 & 44 \\
\hline
\end{tabular}

Table 2

Generally, the findings in the Table above show that lecturers had a number of experiences during their supervision for assessment and grading of teacher trainees. All of them experienced that teacher trainees were liked by the schools and showed commitment and trustworthiness in taking different responsibilities. Lecturers (88.8\%) expressed that there was positive attitude towards teacher trainees by the school leaders and the trainees were ready for assessment and grading which implies that they had confidence on how they were prepared through monitoring. The lecturers (95.5\%) appreciated the mapping of schools which led to convenience in reaching the schools with teacher trainees. About $77.7 \%$ of the lecturers participated in the feedback discussion expressed that most of teacher trainees demonstrated competency in teaching practical subjects in the schools. This finding implies that there is potential improvement in teaching of science lessons practically in the future when the trainees will be employed in the schools throughout the country. Other experiences identified were related to school culture, school schedules, weather changes and transport challenges. The experiences are in support of Nzilano (2013) in the study of Pre-service Teachers' Teaching Competencies, the experience of practicing teaching in secondary schools and Teacher Colleges which the findings identified similar experiences that influence teacher trainees during the teaching practice. 


\subsection{Lessons Learnt through Teaching Practice Supervision}

The teaching practice coordinating team wanted to know if there were new lessons learnt in this year (2017) Block Teaching Practice. When asked to explain the lessons they learnt in teaching practice they had the following from the group discussion.

\begin{tabular}{|c|c|c|c|}
\hline S/ No & Lessons & F & \% \\
\hline 1 & $\begin{array}{c}\text { Learned that the Teaching Practice orientation had a lot of improvement this year to } \\
\text { lecturers, students and monitors as there were a lot of similarities on how things are } \\
\text { supposed to be done. The BTP orientation team was very strong. }\end{array}$ & 45 & 100 \\
\hline 2 & $\begin{array}{c}\text { There was a great cooperation between the student teachers and their lecturers who } \\
\text { supervised them }\end{array}$ & 44 & 97.7 \\
\hline 3 & $\begin{array}{c}\text { The university lecturers acknowledged that they also learnt from the teacher trainee's } \\
\text { contents when they were presenting lessons by using different teaching techniques }\end{array}$ & 40 & 88.8 \\
\hline 4 & $\begin{array}{c}\text { Multiple learner centered teaching techniques were appropriately used and reflects } \\
\text { what they were taught in class was effective. }\end{array}$ & 45 & 100 \\
\hline 5 & $\begin{array}{c}\text { Monitoring of students during teaching practice has a great influence in the teacher } \\
\text { trainee's confidence i.e. Those who received the monitoring they had more confidence } \\
\text { and did well in their presentations as compare to those who did not }\end{array}$ & 45 & 100 \\
\hline 6 & $\begin{array}{c}\text { Schools want more teacher trainees from MWECAU to conduct teaching practice in } \\
\text { their schools }\end{array}$ & 43 & 95.5 \\
\hline 7 & $\begin{array}{c}\text { Government secondary schools do not have science teachers and so they have higher } \\
\text { needs for the science teacher trainees to help their students learn science subjects }\end{array}$ & 45 & 100 \\
\hline 8 & $\begin{array}{c}\text { Teacher trainees were friendly to the students they were teaching which helped them } \\
\text { to take care for those with learning difficulties through the remedial classes. }\end{array}$ & 42 & 93.3 \\
\hline 9 & $\begin{array}{c}\text { Many secondary schools are continuing using corporal punishment as a method of } \\
\text { dealing with student's problems and hence discourage some of the teacher trainees. }\end{array}$ & 28 & 62.2 \\
\hline 10 & $\begin{array}{c}\text { Teacher trainees discipline was excellent in both inside and outside the schools. This } \\
\text { was reflected from the heads of schools and teachers when they were giving feedback } \\
\text { to the university supervisors during assessment }\end{array}$ & 43 & 95.5 \\
\hline 11 & $\begin{array}{c}\text { The feedback knowledge and skills learnt during the BTP orientation was very } \\
\text { powerful to both the teacher trainees and the supervisors. The sessions were very } \\
\text { constructive and well handled which lead to smooth discussions among the ones who } \\
\text { were engaged in the activity. }\end{array}$ & 45 & 100 \\
\hline
\end{tabular}

Table 3

All the lecturers learnt that, orientation of both lecturers and teacher trainees is a powerful tool in achieving block teaching practice goals. The monitoring during teaching practice opened teacher trainee's eyes on appropriate teaching experiences and competence while the same activity improved trainees' readiness to receive teaching practice feedback. About $95.5 \%$ of the lecturers learnt that the teacher's trainees showed discipline and considered teacher profession code of conduct positively which helped them to share and receive support from the experienced teachers in the schools. These support Mergler \& Spooner-Lane (2012) who found that teacher trainees have to develop values that are basic to the profession for better practice. The lecturers learnt that, the trainees were equipped with relevant subject matter and were able to apply multiple learner centered techniques which helped to make lessons interesting and interactive.

They all learnt that, there is a serious challenge of shortage of science teachers in the government schools which to some extent affected science teacher trainees since they did not receive accorded help from experienced science teachers. This implies that the government should put efforts to employ science teachers to its schools in order to improve science teaching and learning in schools. Majority (62.2\%) of lecturers learnt that many teachers in secondary schools they visited for supervision are still applying corporal punishment either during teaching or in dealing with students discipline outside classrooms. This reveals that there is need for refreshing the experience teacher on positive discipline techniques such as avoiding punishing entire class, fairness, love to the students, among others to enhance school learning environment. Generally, the lessons meant to identify areas that can be strengthen in the implementation of pre-service teacher training programme at the university but also aspects to stress during the BTP orientation.

\subsection{Block Teaching Practice Strengths}

The monitors paved the way for the effective teaching practice supervision as they provided the teacher trainees most supportive skills which they used during their teaching and to minimize the possibilities of making errors in teaching and thus more effective teaching experience in addition, monitors were able to build the teacher professional competence in the teacher trainees which made them to score relatively higher than those who were not able to receive the same assistance. Most of teacher trainees left a lasting mark to the secondary schools they conducted their teaching practice. This was brought about 
due their commitment to work, love of work and redness to accept and do duties assigned to them. Some of the teacher trainees were assigned duties such as of chairing staff meetings, class teachers, discipline teachers and all of them were assigned to be teacher on duties. About $82 \%$ agreed on this and expressed their positive comments on the impressions that were left by the teacher trainees in the schools. This shows that the prospective employers were able to get the good image of the nature of the teacher graduates from MWECAU thus open to job market.

Most teacher trainees (97\%) observed the professional code of conduct including dress code, punctuality, obedience to the authority, care and protection to their students and human rights as stipulated in the public servant's regulations. The teacher trainee's sense of value for work gave credits and some of the heads and teachers in the schools requested for the needs to have teaching practice sessions in ten weeks to learn new knowledge and skills from them.

The positive feedback from heads of schools and academic teachers on the student's discipline indicate that the students demonstrated a high degree of professionalism. Majority (85\%) of the lecturers said that some heads of schools were sad because the trainees were going to stay for only five weeks where as they had become the role model for the rest of teachers in discipline and commitment to work and the service they rendered to their schools. The findings here concur with Orr, et al (2013) who asserts that, the teachers' education should provide adequate time for practical training to its trainees for them to be exposed to the multiple professional experiences.

\section{Suggestions on How to Improve}

The participants in the discussion were given opportunity to share the suggestions on areas for improvement to enhance BTP and they came up with the following:

Expand the scope of monitoring programme to cover all the teacher trainees. About $95 \%$ of the lecturers participated in the feedback session came up with this suggestion because of the differences observed from the trainees who received monitoring feedback and those without the similar support. Their suggestion could be of paramount help to the setting up of the new proposal for next years' Block Teaching Practices. Majority of the lecturers 78\% acknowledged the differences in the performance of the teacher trainees who received monitoring and those who did not.

The Block Teaching Practice coordinating team should propose and take the serious measures on the teacher trainees and lecturers who do not attend the orientation to avoid confusions on the understanding of the BTP changes and issues such as in lesson preparations and the assessment objectivity. Lecturers also proposed that those lecturers who will not participate in the orientation workshop should not be allocated students for supervision as the quality of the exercise begins with the proper orientation of what one is expected to do in the actual practice. About $75 \%$ of the lecturers attended the feedback discussion proposed that Block Teaching Practice zones should be expanded to cover Lake Zone regions and some regions in the south of Tanzania for the good practices to spread.

\section{References}

i. Kagoda, A.M \&Sentongo, J. (2015). Practicing Teachers' perceptions of Teacher Trainees: Implications for Teacher Education. Uganda: Makerere University.

ii. Mergler, A. G. \& Spooner-Lane, R. (2012). What Pre-service Teachers need to know to be Effective at Values-based Education: Australian Journal of Teacher Education (Vol 37). Australia: Queensland University of Technology.

iii. Mushi, L. J and Lasway A. J. (2017). Higher Learning Students Expectations: implications and achievements. A case study of Mwenge Catholic University Tanzania. International

iv. Journal of Scientific and Education Research. Vol.1, No.01 pp.97-112.

v. Nzilano, J.L. (2013). Pre-service Teachers' Teaching Competencies: The Experience of Practicing Teaching in Secondary Schools and Teacher Colleges. Dar es Salaam:Dar es Salaam University.

vi. Orr, Det al (2013). Pedagogy, Curriculum, Teaching Practices and Teacher education in Developing countries. US: University of Sussex.

vii. The United Republic of Tanzania. (2014). Education and Training Policy. Dar es salaam.

viii. Vumilia, P.L. \&Semali, L. M. (2015. Vol 2). Can the Mentoring and Socialization of Pre-service Teachers Improve Teacher Education?: Journal of International Education and Leadership. Pennsylvania: Pennsylvania State University. 